\title{
Increased Neurogenesis in the Dentate Gyrus After Transient Global Ischemia in Gerbils
}

\author{
Jialing Liu, ${ }^{1}$ Karen Solway, ${ }^{1}$ Robert O. Messing, ${ }^{2}$ and Frank R. Sharp ${ }^{1}$ \\ ${ }^{1}$ Departments of Neurology and Neurosurgery, University of California at San Francisco and San Francisco Veterans \\ Affairs Medical Center, San Francisco, California 94121, and '2Department of Neurology, Ernest Gallo Clinic and Research \\ Center and Graduate Programs in Neuroscience and Biomedical Sciences, University of California at San Francisco, \\ San Francisco, California 94110
}

Neurogenesis in the dentate gyrus of adult rodents is regulated by NMDA receptors, adrenal steroids, environmental stimuli, and seizures. To determine whether ischemia affects neurogenesis, newly divided cells in the dentate gyrus were examined after transient global ischemia in adult gerbils. 5-Bromo-2'deoxyuridine-5'-monophosphate (BrdU) immunohistochemistry demonstrated a 12-fold increase in cell birth in the dentate subgranular zone 1-2 weeks after 10 min bilateral common carotid artery occlusions. Two minutes of ischemia did not significantly increase BrdU incorporation. Confocal microscopy demonstrated that BrdU immunoreactive cells in the granule cell layer colocalized with neuron-specific markers for neuronal nuclear antigen, microtubule-associated protein-2, and calbindin $D_{28 k}$, indicating that the newly divided cells migrated from the subgranular zone into the granule cell layer and matured into neurons. Newborn cells with a neuronal phenotype were first seen $26 \mathrm{~d}$ after ischemia, survived for at least 7 months, were located only in the granule cell layer, and comprised $\sim 60 \%$ of BrdU-labeled cells in the granule cell layer 6 weeks after ischemia. The increased neurogenesis was not attributable to entorhinal cortical lesions, because no cell loss was detected in this region. Ischemic preconditioning for $2 \mathrm{~min}$, which protects CA1 neurons against subsequent ischemic damage, did not prevent increased neurogenesis in the granule cell layer after a subsequent severe ischemic challenge. Thus, ischemia-induced dentate neurogenesis is not attributable to CA1 neuronal loss. Enhanced neurogenesis in the dentate gyrus may be a compensatory adaptive response to ischemiaassociated injury and could promote functional recovery after ischemic hippocampal injury.

Key words: neurogenesis; dentate gyrus; granule neuron; cerebral ischemia; hippocampus; CA1; NMDA receptor; entorhinal cortex; neural stem cells; BrdU; NeuN; GFAP; MAP-2; calbindin; spreading depression; subependyma; erythropoietin; FGF; BDNF
Neural stem cells, with self-renewal and multilineage potential, have been identified in the embryonic and adult mammalian brain (Weiss et al., 1996; McKay, 1997). Neurogenesis in the adult mammalian brain is limited to two regions, the dentate gyrus of the hippocampus and the olfactory bulb (Altman and Das, 1967; Kaplan and Hinds, 1977; Kaplan and Bell, 1983, 1984). The progenitor cells giving rise to new neurons for these areas are located in the dentate gyrus and subependyma, respectively. Hippocampal progenitor cells from adult rat brain proliferate and differentiate into neurons and glia in vitro when maintained in medium containing FGF-2 (Gage et al., 1995). Progenitor cells that are grafted into the adult brain develop into mature neurons, with morphological and biochemical features characteristic of the surrounding neurons. This suggests that CNS stem cells are capable of responding to environmental cues in the adult host (Suhonen et al., 1996). The ability of neural stem cells to integrate into various brain regions offers hope for the development of

Received May 29, 1998; revised July 22, 1998; accepted July 23, 1998.

This work was supported by National Institutes of Health Grants R01 NS28167, NS14543, and HL53040 (F.R.S.). We thank Drs. Jack Parent and Steve Massa for their suggestions and comments and Dr. Holger Wille and Mr. Ed Caballero for assistance with the photography.

Correspondence should be addressed to Dr. Jialing Liu, Departments of Neurology and Neurosurgery (V127), University of California at San Francisco and Department of Veterans Affairs Medical Center, 4150 Clement Street, San Francisco, CA 94121.

Copyright (C) 1998 Society for Neuroscience $\quad 0270-6474 / 98 / 187768-11 \$ 05.00 / 0$ restorative therapies for ischemic, traumatic, and degenerative brain diseases. Understanding factors that control stem cell growth and regional differentiation will help achieve such a goal. Grafts of fetal CNS tissue that include CA1 hippocampal cells reverse learning deficits produced by global ischemic damage to CA1 pyramidal neurons in adult rats (Hodges et al., 1996). This finding, along with many similar transplant studies, demonstrates the potential for the anatomical and functional integration of grafts of specific cell types, even in the adult nervous system.

Adrenal steroids (Cameron and Gould, 1994) and excitatory amino acids (Cameron et al., 1995) regulate neurogenesis in the adult dentate gyrus subgranular zone (SGZ). Adrenalectomy, glutamatergic deafferentation, and NMDA receptor antagonists increase neurogenesis in the SGZ, whereas spreading depression (Dziewulska et al., 1996) and adrenal steroids (Gould et al., 1992, 1997; Cameron and Gould, 1994) decrease neurogenesis. Seizures increase dentate granule cell neurogenesis in association with sprouting of mossy fibers into the inner molecular layer of the dentate gyrus (Parent et al., 1997). The present studies were undertaken to determine whether global ischemia, which influences NMDA and other glutamate receptors (Westerberg et al., 1989), also affects dentate neurogenesis. Using immunohistochemistry to detect the incorporation of the thymidine analog 5-bromo-2'-deoxyuridine-5'-monophosphate (BrdU) into newly synthesized DNA, a marked increase in cellular proliferation in the SGZ of the dentate gyrus was observed 1-2 weeks after global 
ischemia. The majority of newborn cells that migrated into the granule cell layer (GCL) expressed neuronal markers, whereas some of the cells that migrated from the SGZ into the dentate hilus became astrocytes. The results indicate that hippocampal progenitor cells give rise to dentate granule cell neurons and hilar astrocytes in response to ischemic injury.

\section{MATERIALS AND METHODS}

Reagents. The following antibodies and final concentrations were used: mouse anti-BrdU $(0.25 \mu \mathrm{g} / \mathrm{ml}$; Boehringer Mannheim, Indianapolis, IN); rat anti-BrdU (2 $\mu \mathrm{g} / \mathrm{ml}$; Accurate Chemicals, Westbury, NY); mouse anti-proliferative cell nuclear antigen (PCNA) $(1 \mu \mathrm{g} / \mathrm{ml}$; Boehringer Mannheim); mouse anti-neuronal nuclear antigen (NeuN) $(1 \mu \mathrm{g} / \mathrm{ml}$; Chemicon, Temecula, CA); mouse anti-microtubule-associated protein 2 (MAP-2) $(1 \mu \mathrm{g} / \mathrm{ml}$; Boehringer Mannheim); rabbit anti-calbindin-D (1:500; SWANT, Bellinzona, Switzerland); and mouse anti-GFAP (1 $\mu \mathrm{g} / \mathrm{ml}$; Chemicon). Biotinylated sheep anti-mouse IgG $(5 \mu \mathrm{g} / \mathrm{ml}$; Amersham, Cleveland, $\mathrm{OH}$ ) served as the secondary antibody for BrdU and NeuN peroxidase immunohistochemistry. The avidin-peroxidase complex solution (Vector laboratories, Burlingame, CA) was used at a dilution of 1:100. ExtrAvidin-fluorescein 5'-isothiocyanate (FITC) $(10 \mu \mathrm{g} /$ $\mathrm{ml}$; Sigma, St. Louis, MO), Cy-3-labeled goat anti-mouse IgG $(1 \mu \mathrm{g} / \mathrm{ml}$; Amersham), and Cy-3-labeled goat anti-rabbit IgG (1 $\mu \mathrm{g} / \mathrm{ml}$; Amersham) were used as fluorescent labels. Three different antibodies to neuronal proteins were used because of the concern that ischemia might induce neuronal proteins in non-neuronal cells (Toyoshima et al., 1996).

Transient global ischemia. Adult male Mongolian gerbils (11-13 weeks of age; Simmonson, Gilroy, CA) were used for these studies. The animals were anesthetized with $3 \%$ isoflurane in $20 \% \mathrm{O}_{2}-77 \% \mathrm{~N}_{2}$. After bilateral neck incisions, both common carotid arteries (CCAs) were exposed and occluded with aneurysm clips for 2-10 min. The clips were then removed to restore cerebral blood flow. The rectal temperature was maintained at $37^{\circ} \pm 0.5^{\circ} \mathrm{C}$ with a heating blanket until the animals recovered from surgery. After recovery, the animals were monitored for an additional 2 $\mathrm{hr}$ to prevent hypothermia. Sham-operated animals were treated identically, except that the CCAs were not occluded after the neck incisions. A separate group of gerbils was anesthetized and underwent ischemic preconditioning produced by bilateral occlusion of the CCAs for $2 \mathrm{~min}$ (Kirino et al., 1991; Kitagawa et al., 1991; Liu et al., 1997). Three days later, these animals were reanesthetized, and both CCAs were occluded for $5 \mathrm{~min}$.

BrdU labeling. The thymidine analog BrdU was administered intraperitoneally $(50 \mathrm{mg} / \mathrm{kg}$; Sigma, St. Louis, MO). Two injection paradigms were used. In some experiments (see Figs. 1, 2, 6), we gave a single dose of BrdU and killed the animals the next day. This allowed us to measure the number of cells that incorporated BrdU during a $24 \mathrm{hr}$ period and provided an index of the rate of cell birth at a specific time point after ischemia. In other experiments (see Figs. 3, 4; Table 1), we gave injections of $\mathrm{BrdU}(50 \mathrm{mg} / \mathrm{kg})$ twice daily for 4 consecutive days during the peak of cell proliferation 9-12 d after ischemia. This allowed us to investigate the phenotype, survival, and migration pattern of newborn cells.

Tissue preparation and immunohistochemistry. Animals were anesthetized with ketamine $(80 \mathrm{mg} / \mathrm{kg}$; Parke-Davis, Morris Plains, NJ) and xylazine $(20 \mathrm{mg} / \mathrm{kg}$; Butler, Columbus, $\mathrm{OH})$. They were perfused transcardially with $0.9 \%$ saline, followed by $4 \%$ paraformaldehyde (PFA) in $0.1 \mathrm{M}$ phosphate buffer, $\mathrm{pH} 7.4(\mathrm{~PB})$. The brains were removed, post-fixed for $6 \mathrm{hr}$ in $4 \% \mathrm{PFA}-\mathrm{PB}$, and placed in $40 \%$ sucrose overnight. Fifty micrometer coronal sections were cut on a vibratome and stored in PB. Representative sections were placed on gelatin-coated slides and stained with cresyl violet.

For immunocytochemical detection of BrdU-labeled nuclei, DNA was denatured to expose the antigen. Before incubation in anti-BrdU primary antibody, free-floating brain sections were pretreated in $50 \%$ formamide $-2 \times \mathrm{SSC}$ at $65^{\circ} \mathrm{C}$ for $2 \mathrm{hr}$ and then incubated at $37^{\circ} \mathrm{C}$ for $30 \mathrm{~min}$ in $2 \mathrm{~N} \mathrm{HCl}$. Finally, sections were rinsed for $10 \mathrm{~min}$ at $25^{\circ} \mathrm{C}$ in $0.1 \mathrm{M}$ boric acid, $\mathrm{pH} 8.5$. Sections were then incubated overnight at $25^{\circ} \mathrm{C}$ in primary antibody diluted in $\mathrm{PB}$ with $1 \%$ sheep serum, $0.1 \%$ bovine serum albumin, and $0.3 \%$ Triton X-100. After being washed in PB, sections were incubated in biotinylated secondary antibody for $2 \mathrm{hr}$ at $25^{\circ} \mathrm{C}$. After three 5 min rinses in $\mathrm{PB}$, sections were placed in avidin-peroxidase complex solution containing avidin-peroxidase conjugate for $2 \mathrm{hr}$. After two more $5 \mathrm{~min}$ washes, sections were incubated for $2 \mathrm{~min}$ in a peroxidase reaction solution $\left(0.25 \mathrm{mg} / \mathrm{ml}\right.$ diaminobenzidine, $0.01 \% \mathrm{H}_{2} \mathrm{O}_{2}$, and $\left.0.04 \% \mathrm{NiCl}_{2}\right)$.
Peroxidase staining was examined using a Leitz (Wetzlar, Germany) Orthoplan microscope.

Immunofluorescence. Sections were incubated overnight with rat anti$\mathrm{BrdU}$ and then for $2 \mathrm{hr}$ in biotinylated sheep anti-rat antibody. Sections were then incubated with ExtrAvidin-FITC conjugate for $2 \mathrm{hr}$. After two 5 min PB washes, they were incubated with mouse anti-NeuN, mouse anti-MAP-2, rabbit anti-calbindin, or mouse anti-GFAP antibodies overnight. This was followed by incubation for $2 \mathrm{hr}$ with Cy-3-labeled goat anti-mouse or goat anti-rabbit secondary antibodies. Sections were washed in PB and then mounted with coverslips on glass slides. Fluorescence was detected using a Bio-Rad (Richmond, CA) MRC 1024 confocal imaging system equipped with a krypton-argon laser and a Nikon Diaphot microscope. Images $(512 \times 512$ pixels $)$ were obtained by averaging six scans and were processed by Adobe Photoshop (Adobe Systems, Mountain View, CA).

Cell counting. The number of BrdU immunoreactive nuclei in the SGZ was counted in five to seven coronal hippocampal sections $(50 \mu \mathrm{m})$ per animal. The sections were spaced $200 \mu \mathrm{m}$ apart and spanned the septal (dorsal) hippocampus. Each microscope image was digitized. BrdU immunoreactive nuclei were counted on a computer monitor to improve visualization and in one focal plane to avoid over-sampling. The area of the dentate gyrus, including the hilus, SGZ, and inner third of the GCL, was measured on each section using a computer-based microcomputer imaging device imaging system (Imaging Research, Inc., Ontario, Canada). The density of BrdU immunoreactive cells in each section was calculated by dividing the number of BrdU-positive nuclei by the area of the dentate gyrus. Density for the five to seven sections were averaged to obtain a mean density value for each animal. Differences between mean values for each treatment group were analyzed using the Kruskal-Wallis ANOVA on ranks, followed by post hoc tests using Dunn's method (SigmaStat; Jandel Scientific, San Rafael, CA). Differences were considered significant when $p<0.05$

Colocalization of NeuN or GFAP immunoreactivity with BrdU immunoreactivity was examined in the GCL, SGZ, and dentate hilus. The number of BrdU immunoreactive cells in each region was counted using a fluorescent microscope. To obtain the proportion of BrdU-labeled cells that were neurons or astrocytes, we used confocal microscopy to detect the percentage of BrdU-labeled cells immunoreactive for NeuN or GFAP. This was done by examining cells in 7-10 random fields within each brain region per animal. Estimates of the numbers of neurons and astrocytes were calculated by multiplying these percentages by the total number of BrdU-labeled cells in each region (see Table 1)

\section{RESULTS}

\section{Upregulation of cell proliferation in the dentate gyrus after global ischemia}

There was a basal level of BrdU incorporation into cells in the SGZ of control animals $24 \mathrm{hr}$ after labeling (Fig. 1A). This is an area in which neurogenesis normally persists in adult animals (Kaplan and Hinds, 1977; Stanfield and Trice, 1987; Cameron et al., 1993). BrdU-labeled nuclei in the SGZ of both control and ischemic brains appeared as irregularly shaped clusters located exclusively in the SGZ (Fig. 1). This pattern is characteristic of dentate gyrus progenitor cells (Cameron et al., 1995; Gould et al., 1997). The number of BrdU-labeled cells was not changed by sham operation or $2 \mathrm{~min}$ of global ischemia (Fig. $2 B$ ), demonstrating that the stress of surgery did not increase cell proliferation.

BrdU incorporation did not significantly increase during the first $6 \mathrm{~d}$ after global ischemia (Fig. 2A). Thereafter, cell proliferation increased markedly and was maximal $11 \mathrm{~d}$ after ischemia, with a 12-fold increase in BrdU immunoreactive nuclei per square millimeter dentate gyrus compared with control animals. Cell proliferation decreased by $14 \mathrm{~d}$ after ischemia but was still greater than control (Figs. $1 C, 2 A$ ). Although the number of dividing cells appeared to return to control levels in most animals 3-5 weeks after ischemia (Fig. 2A), a few animals continued to demonstrate increased cell birth at these times (Fig. $1 D, E$ ).

To examine the relationship between the duration of ischemia 

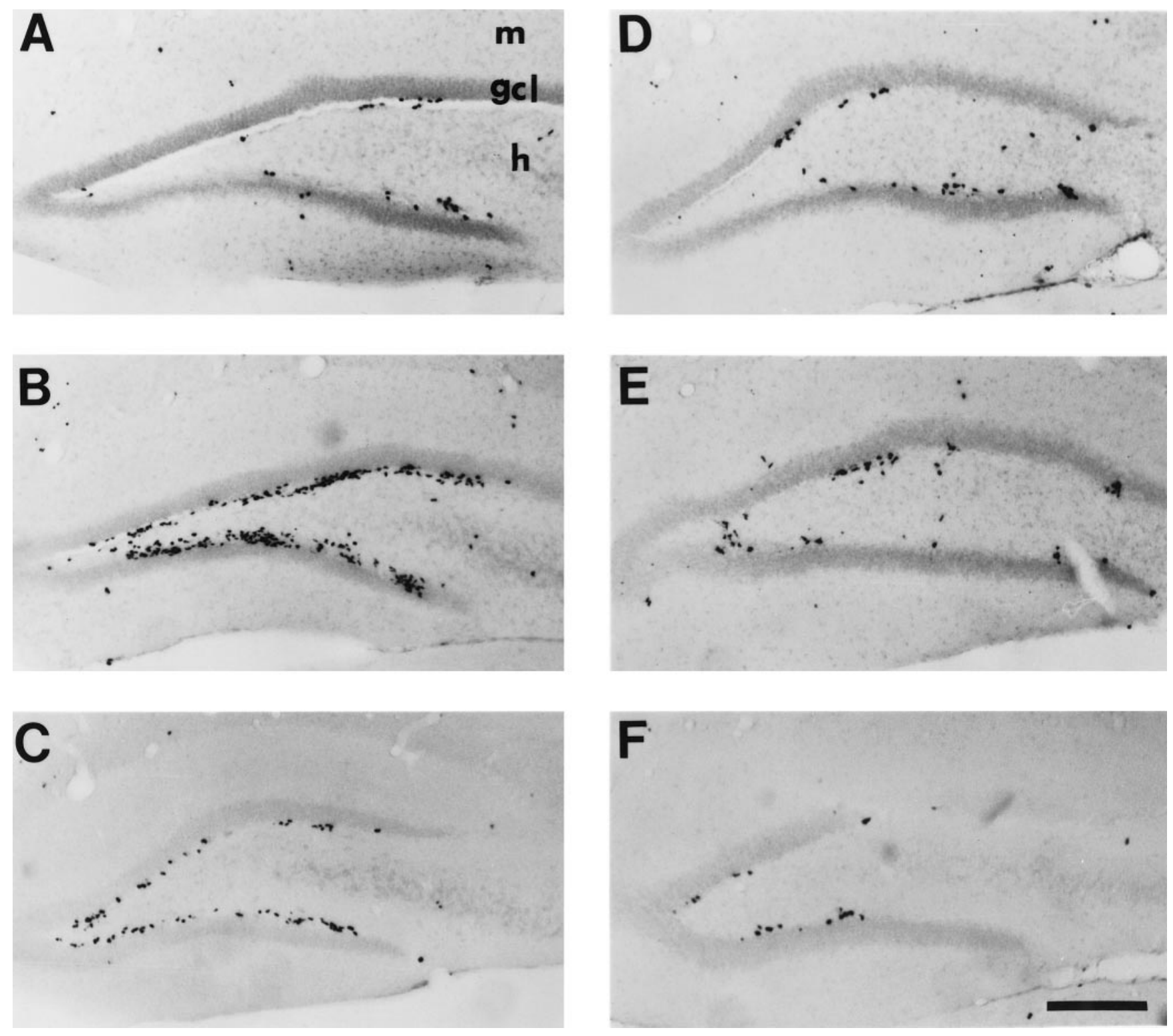

Figure 1. Ischemia increases cell proliferation in the dentate gyrus of adult gerbils. Animals were subjected to 10 min of global ischemia. BrdU was administered $1 \mathrm{~d}$ before the animal was killed, and brains were processed for BrdU immunohistochemistry. $A$, Control untreated gerbil. $B-F$, Ischemic gerbils killed $8 \mathrm{~d}(B), 2$ weeks $(C), 3$ weeks $(D)$, 4 weeks $(E)$, or 5 weeks $(F)$ after ischemia. Scale bar, $250 \mu \mathrm{m}$.

and cell proliferation, gerbils were subjected to global ischemia for 2-10 $\mathrm{min}$ and allowed to recover. They were injected with BrdU (50 mg/kg) $8 \mathrm{~d}$ later and killed the next day (Fig. 2B). There was no increase in the number of labeled cells after 2 min of ischemia. However, there was a steep rise in the number of BrdU immunoreactive cells, as the duration of ischemia increased to $4 \mathrm{~min}$. When ischemia was prolonged to $10 \mathrm{~min}$, there was only a slight increase in the number of BrdU-labeled cells compared with 4 min (Fig. 2B).

\section{Ischemia-induced neurogenesis in the dentate gyrus}

To determine whether proliferating cells in the SGZ became neurons, we examined hippocampal sections from animals killed 15-40 d after a single 10 min episode of ischemia (Fig. 3, Table 1). For these studies, animals received multiple BrdU $(50 \mathrm{mg} / \mathrm{kg})$ injections 9-12 d after ischemia to maximally label proliferating cells (Fig. 2A). Fifteen days after ischemia, labeled cells did not express neuronal or astrocyte markers (Table 1). However, $26 \mathrm{~d}$ after ischemia, $27 \%$ of the BrdU immunoreactive cells in the GCL and SGZ expressed NeuN (Table 1). The percentage of NeuN-expressing BrdU immunoreactive cells (Fig. $3 B$ ) increased to $61 \%$ (Table 1) $40 \mathrm{~d}$ after ischemia. At this time, the majority of the BrdU-labeled nuclei in the GCL colocalized with calbindin-D ${ }_{28 \mathrm{k}}$ (Fig. 3A), NeuN (Fig. 3B), and MAP-2 (Fig. 3C) immunoreactive cells. Some BrdU-labeled cells did not express these neuronal markers (Fig. $3 A$, arrowhead). A similar increase in the percentage of BrdU-labeled cells expressing $\mathrm{NeuN}$ was observed in control animals over time (Table 1).

The location of BrdU-labeled cells changed over time. Fifteen days after global ischemia, most labeled cells were located in the SGZ (Fig. 4A). Twenty-six days after ischemia, some of the cells were still in the SGZ, but many were found throughout the GCL (Fig. 4B). Forty (Fig. 4C) and 96 (Fig. 4D) d after ischemia, large 

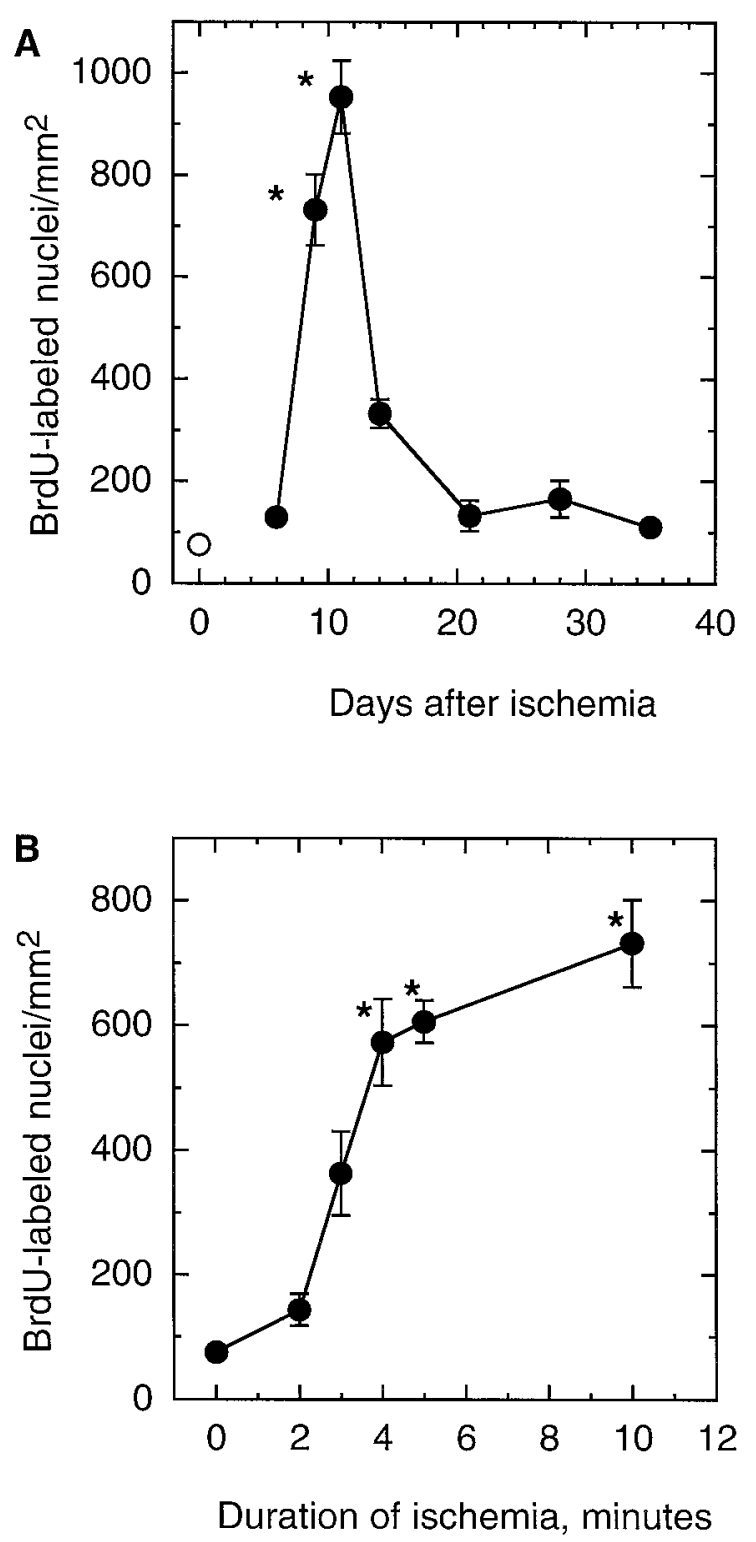

Figure 2. Time course of cell proliferation after global ischemia and effect of ischemia duration on proliferation in the SGZ. In both sets of experiments, BrdU was administered $24 \mathrm{hr}$ before the animal was killed. $A$, The number of BrdU immunoreactive nuclei in the SGZ of animals killed $6 \mathrm{~d}(n=12), 9 \mathrm{~d}(n=8), 11 \mathrm{~d}(n=7), 2$ weeks $(n=6), 3$ weeks $(n=7), 4$ weeks $(n=8)$, or 5 weeks $(n=6)$ after 10 min of global ischemia ( $)$. Control animals $(n=10)$ were untreated $(\bigcirc)$. $B$, BrdUpositive nuclei in the SGZ of animals killed $8 \mathrm{~d}$ after $2(n=8), 3(n=6)$, $4(n=6), 5(n=6)$, or $10(n=8)$ min of ischemia. Data are mean \pm SEM. Error bars are omitted where they extend beyond the symbols. ${ }^{*} p<0.05$ compared with control.

numbers of newborn cells were found throughout the dentate GCL. Many of these cells survived for at least 7 months after ischemia (data not shown).

There was also a marked change in the morphology of BrdUlabeled nuclei in the dentate gyrus in the weeks after ischemia. By the fifteenth day, most nuclei in the SGZ and the edge of the GCL were elongated in shape (Fig. $4 F$ ). Forty days after ischemia, most BrdU-labeled nuclei appeared round like those of surrounding granule neurons (Fig. $4 H$ ). The intensity of BrdU labeling was less in some cells (Fig. 3A, arrows), suggesting that they were derived from labeled precursors that had undergone several divisions, resulting in dilution of BrdU-labeled DNA.

Unlike the dentate gyrus of animals subjected to pilocarpineinduced seizures (Parent et al., 1997) and humans with epileptic damage (Houser, 1990), there was no granule cell dispersion or ectopic granule cell migration after ischemic injury. Some BrdUlabeled cells that migrated a short distance into the dentate molecular layer (Fig. 4I, arrows) expressed NeuN (data not shown). However, NeuN-positive neuronal nuclei were also observed short distances from the GCL in control animals (Fig. 5B).

\section{Dentate gyrus progenitor cells give rise to astrocytes in the hilus}

An increasing number of BrdU-labeled cells also appeared in the dentate hilus in the weeks after ischemia. Approximately $30 \%$ of cells derived from dentate progenitor cells survived and migrated into the dentate hilus by $26 \mathrm{~d}$ after ischemia (Table 1 ). Among the BrdU-labeled population in the hilus, $25 \%$ expressed GFAP $40 \mathrm{~d}$ after ischemia. No BrdU-labeled cells in the dentate hilus expressed $\mathrm{NeuN}$ at any time point examined.

\section{Neuronal loss in the entorhinal cortex or CA1 is not required for dentate neurogenesis after ischemia}

Specific neurons of the entorhinal cortex project to the dentate gyrus (Steward, 1976; Bartesaghi et al., 1995; Deller et al., 1996). Lesions of entorhinal cortex, which remove afferent input to granule neurons, increase neurogenesis in the dentate gyrus (Cameron et al., 1995). To determine whether ischemia-induced hippocampal neurogenesis was associated with injury to entorhinal cortex, we examined brain sections using NeuN immunohistochemistry, cresyl violet staining, and terminal deoxynucleotidyl transferase-mediated biotinylated UTP nick end labeling (TUNEL). There was extensive neuronal loss in the lateral striatum (Fig. 5D) and in the CA1 sector of the hippocampus (Fig. $5 E$ ) after $10 \mathrm{~min}$ of global ischemia. There was also neuronal loss in neocortical layers II-V in most ischemic animals (data not shown). However, there was no cell loss in the entorhinal cortex of ischemic (Fig. 5F) compared with control (Fig. 5C) brains. In addition, there were no TUNEL-labeled or darkly stained pyknotic cells in the entorhinal cortex 1-5 d after global ischemia (data not shown). These results indicate that entorhinal cell death is not associated with $10 \mathrm{~min}$ of global ischemia and is unlikely to be the cause of ischemia-induced neurogenesis in the gerbil hippocampus.

Because ischemia caused loss of CA1 neurons (Fig. $5 E$ ), we considered whether increased dentate neurogenesis was attributable to this. Therefore, cell proliferation was studied in a model of ischemic tolerance. Five minutes of global ischemia alone produced marked CA1 neuronal loss (Fig. 6C). When animals were preconditioned with 2 min of global ischemia and then subjected to $5 \mathrm{~min}$ of global ischemia $3 \mathrm{~d}$ later, $~ 50 \%$ of the animals appeared to have no CA1 neuronal loss (Fig. 6D). This agrees with other studies (Kirino et al., 1991; Kitagawa et al., 1991; Liu et al., 1997). However, there was still a marked increase in neurogenesis in the dentate gyrus of the preconditioned animals that did not show CA1 loss (Fig. 6E). In contrast, 2 min of ischemia alone did not significantly increase proliferation of dentate progenitor cells (Fig. 6E). These results indicate that neurogenesis in the dentate gyrus is not reduced by ischemic preconditioning and does not require CA1 neuronal loss. 

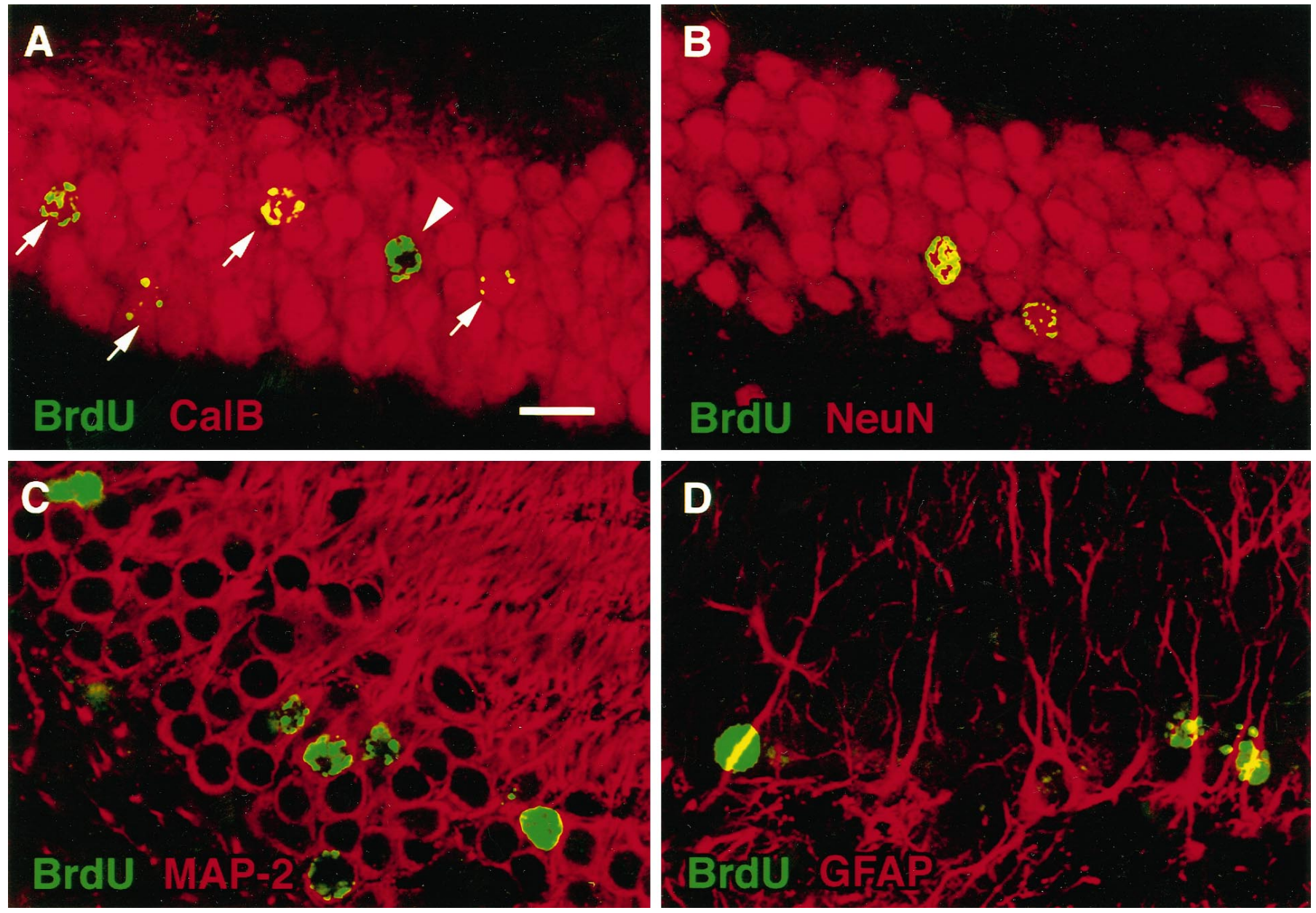

Figure 3. Neuronal identity of newly divided cells in the dentate gyrus after global ischemia. BrdU was administered twice daily $9-12 \mathrm{~d}$ after 10 min of global ischemia. Gerbils were killed 4 weeks later, and brain sections were stained for BrdU immunoreactivity ( green) and cell-specific markers (red). $A, B$, Colocalization of BrdU with calbindin- $\mathrm{D}_{28 \mathrm{k}}(\mathrm{CalB})$ or NeuN is shown by yellow nuclei. $C$, Colocalization of BrdU with MAP-2 is shown in cells with red cytoplasm surrounding green nuclei. $D$, No colocalization of GFAP and BrdU was observed within the GCL. Scale bar, $10 \mu \mathrm{m}$.

Table 1. Quantitative analysis of BrdU immunoreactive cells and their phenotypes in subregions of the dentate gyrus after BrdU labeling ${ }^{a}$

Subregions of the dentate gyrus

\begin{tabular}{|c|c|c|c|c|c|c|c|}
\hline \multirow[b]{3}{*}{ Time after ischemia } & \multirow[b]{3}{*}{ Treatment } & \multicolumn{6}{|c|}{ Subregions of the dentate gyrus } \\
\hline & & \multicolumn{3}{|c|}{$\mathrm{GCL}+\mathrm{SGZ}$} & \multicolumn{3}{|c|}{ Dentate hilus } \\
\hline & & $\operatorname{Total}^{b}$ & $\mathrm{NeuN}^{c}$ & GFAP $^{c}$ & Total & NeuN & GFAP \\
\hline \multirow[t]{2}{*}{$15 \mathrm{~d}$} & Control & $45 \pm 5$ & 0 & 0 & $2 \pm 1$ & 0 & 0 \\
\hline & Ischemia & $220 \pm 57$ & 0 & 0 & $17 \pm 6$ & 0 & $2 \pm 1$ \\
\hline \multirow[t]{2}{*}{$26 \mathrm{~d}$} & Control & $16 \pm 3$ & $3 \pm 1$ & 0 & $3 \pm 1$ & 0 & 0 \\
\hline & Ischemia & $113 \pm 23$ & $30 \pm 5$ & 0 & $69 \pm 37$ & 0 & $7 \pm 3.2$ \\
\hline \multirow[t]{2}{*}{$40 \mathrm{~d}$} & Control & $11 \pm 3$ & $8 \pm 2$ & 0 & $3 \pm 1$ & 0 & 0 \\
\hline & Ischemia & $91 \pm 6$ & $56 \pm 4$ & 0 & $78 \pm 41$ & 0 & $20 \pm 6$ \\
\hline
\end{tabular}

${ }^{a}$ Ischemic and control animals received a series of BrdU injections (50 mg/kg, i.p., twice daily) 9-12 d after surgery.

${ }^{b} \mathrm{BrdU}$ immunoreactive nuclei labeled by FITC detected by immunofluorescence microscopy ( $n=6$ per group).

${ }^{c}$ BrdU-labeled cells also immunoreactive for NeuN or GFAP, as detected by confocal microscopy (see Materials and Methods).

\section{DISCUSSION}

This study provides the first evidence for increased birth of dentate progenitor cells after global ischemia in an adult rodent. Most of these precursor cells migrated out into the GCL from the SGZ, developed into mature neurons, and appeared to integrate into the dentate GCL. Because most BrdU-positive cells did not express NeuN within the first week after BrdU pulse labeling, these cells appear to have required several days to become mature neurons. This delay in maturation contrasts with the more rapid development of ventral horn motor neurons and cerebellar granule cells, which express high levels of NeuN immediately after terminal division of progenitor cells (Mullen et al., 1992).

Within the dentate gyrus, most progenitor cells appeared to differentiate into neurons expressing the neuronal markers NeuN, 

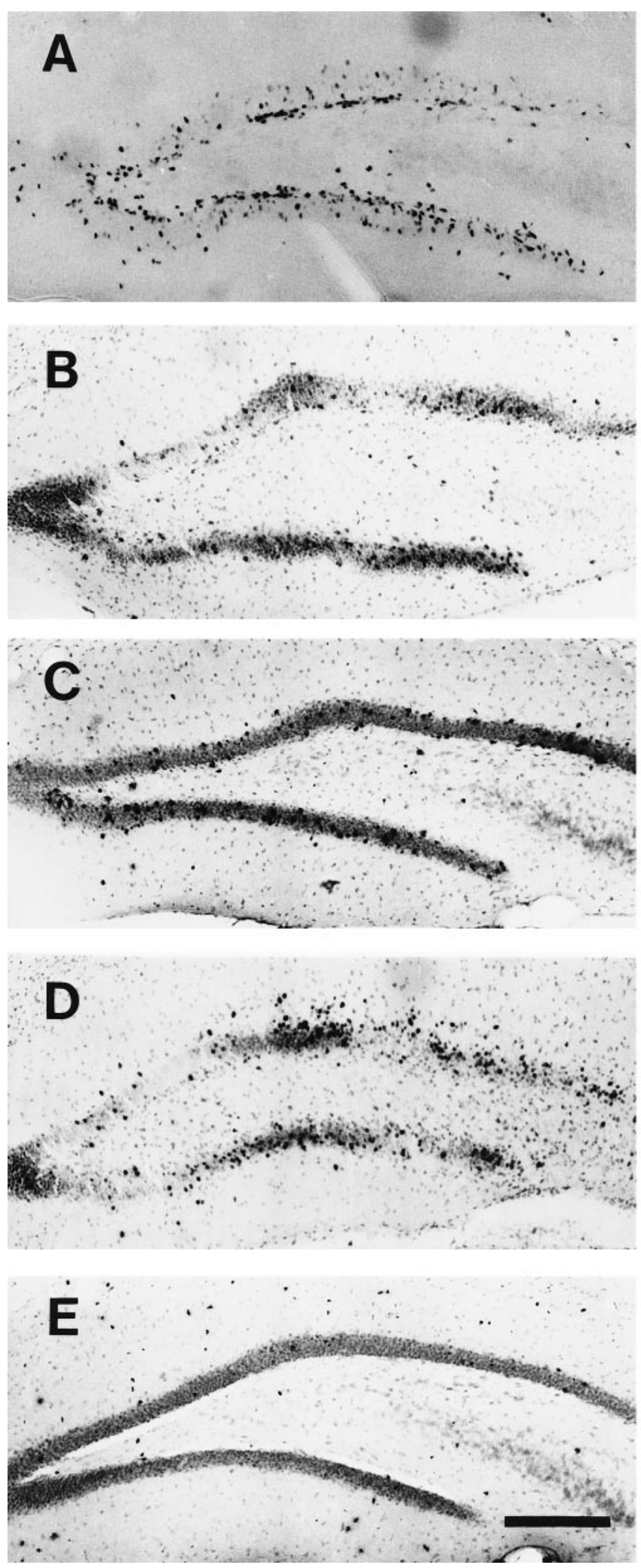
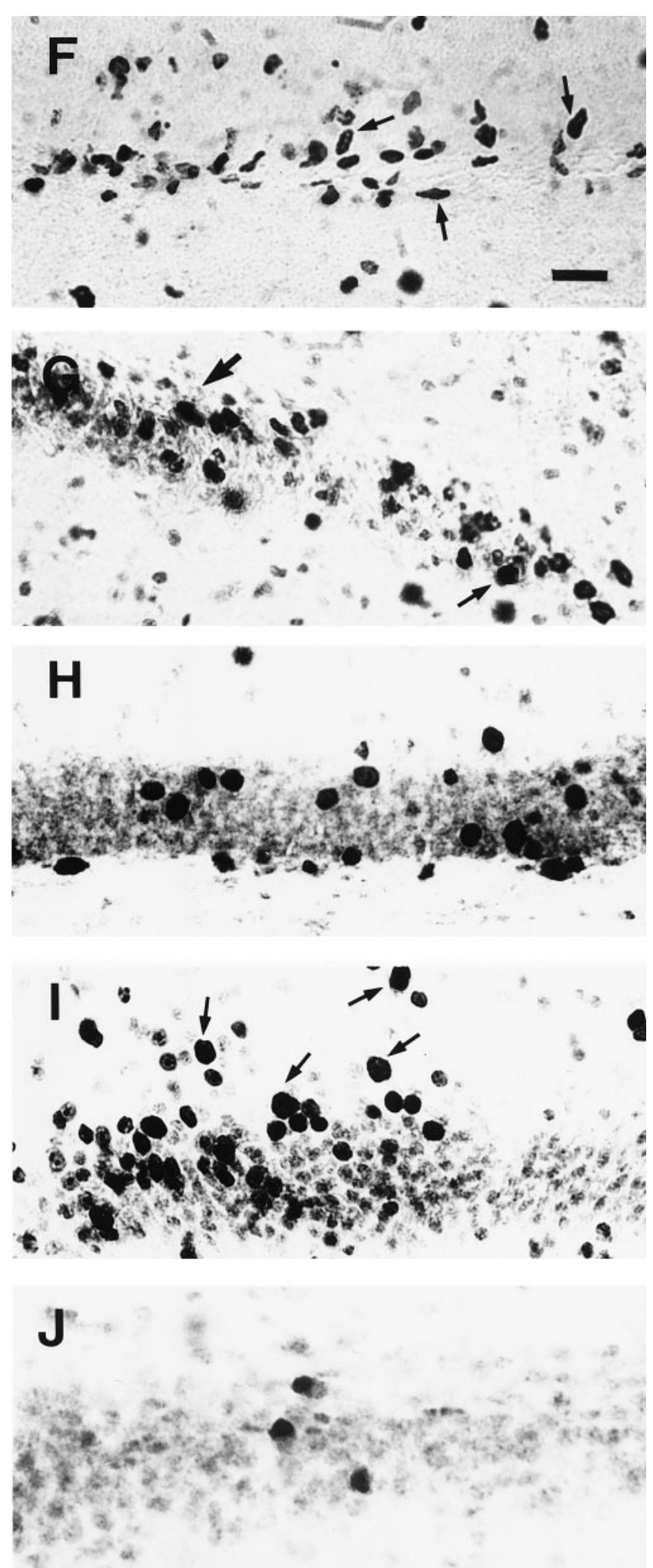

Figure 4. Distribution and morphology of BrdU-labeled cells after global ischemia. BrdU was given twice daily 9-12 d after ischemia. Animals were then killed $15(A, F), 26(B, G), 40(C, H)$, or $96(D, I)$ d after ischemia. The sham-operated gerbil was killed $40 \mathrm{~d}(E, J)$ after surgery. $F-J$, High-magnification view. Scale bars (in $E$ and $F$ ): $A-E, 250 \mu \mathrm{m} ; F-J, 25 \mu \mathrm{m}$. 

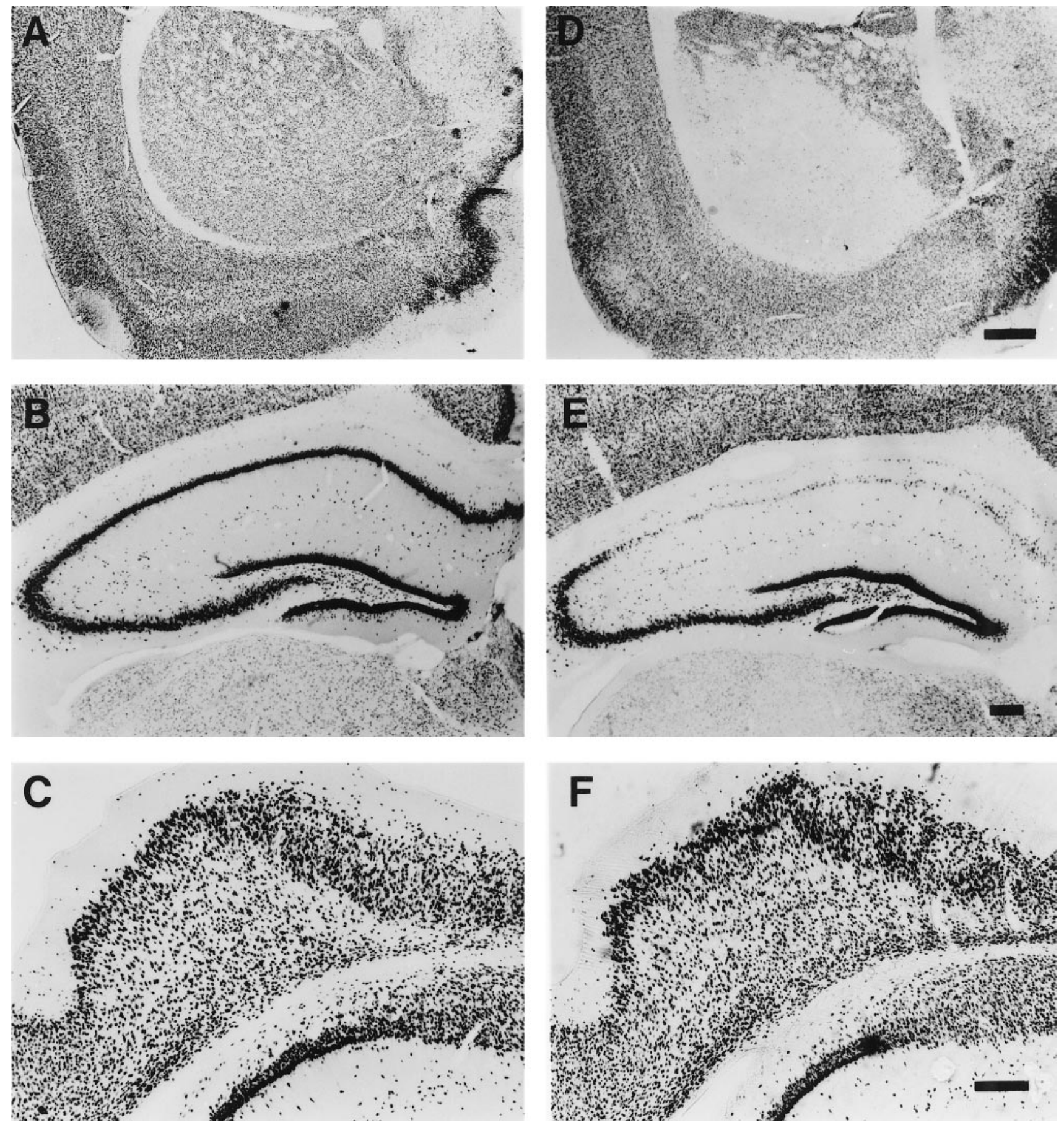

Figure 5. Lack of neuronal loss in the entorhinal cortex after $10 \mathrm{~min}$ of global ischemia. $A-C$, Neuronal cells detected in untreated control gerbils by NeuN immunohistochemistry in striatum $(A)$, hippocampus $(B)$, and entorhinal cortex $(C)$. $D-F$, Animals subjected to 10 min of ischemia and then examined for NeuN immunoreactivity in striatum $(D)$, hippocampus $(E)$, and entorhinal cortex $(F) 8 \mathrm{~d}$ later. Scale bars: (in $D) A, D, 1 \mathrm{~mm}$; (in $E) B$, $E, 200 \mu \mathrm{m}$; (in $F) C, F, 200 \mu \mathrm{m}$.

calbindin-D ${ }_{28 \mathrm{k}}$ (Sloviter et al., 1989), and MAP-2 (Bernhardt and Matus, 1984). The percentage of BrdU immunoreactive cells in the GCL expressing mature neuronal markers increased to $>60 \%$ during the first month after BrdU labeling in both control and ischemic animals. This is consistent with the observation of Cameron et al. (1993), who found that the percentage of $\left[{ }^{3} \mathrm{H}\right]$ thymidine-labeled cells in the GCL that expressed neuronspecific enolase increased to $70 \%$ over 3 weeks after $\left[{ }^{3} \mathrm{H}\right]$ thymi- dine injection. After ischemia, however, not all BrdU progenitors became neurons. A subpopulation of newly divided cells migrated into dentate hilus and became astrocytes. This may have occurred because different environmental cues present in the dentate gyrus and dentate hilus influenced the developmental fate of CNS progenitors.

A substantial number of BrdU-labeled cells in the dentate gyrus and dentate hilus did not express neuronal or astrocytic 

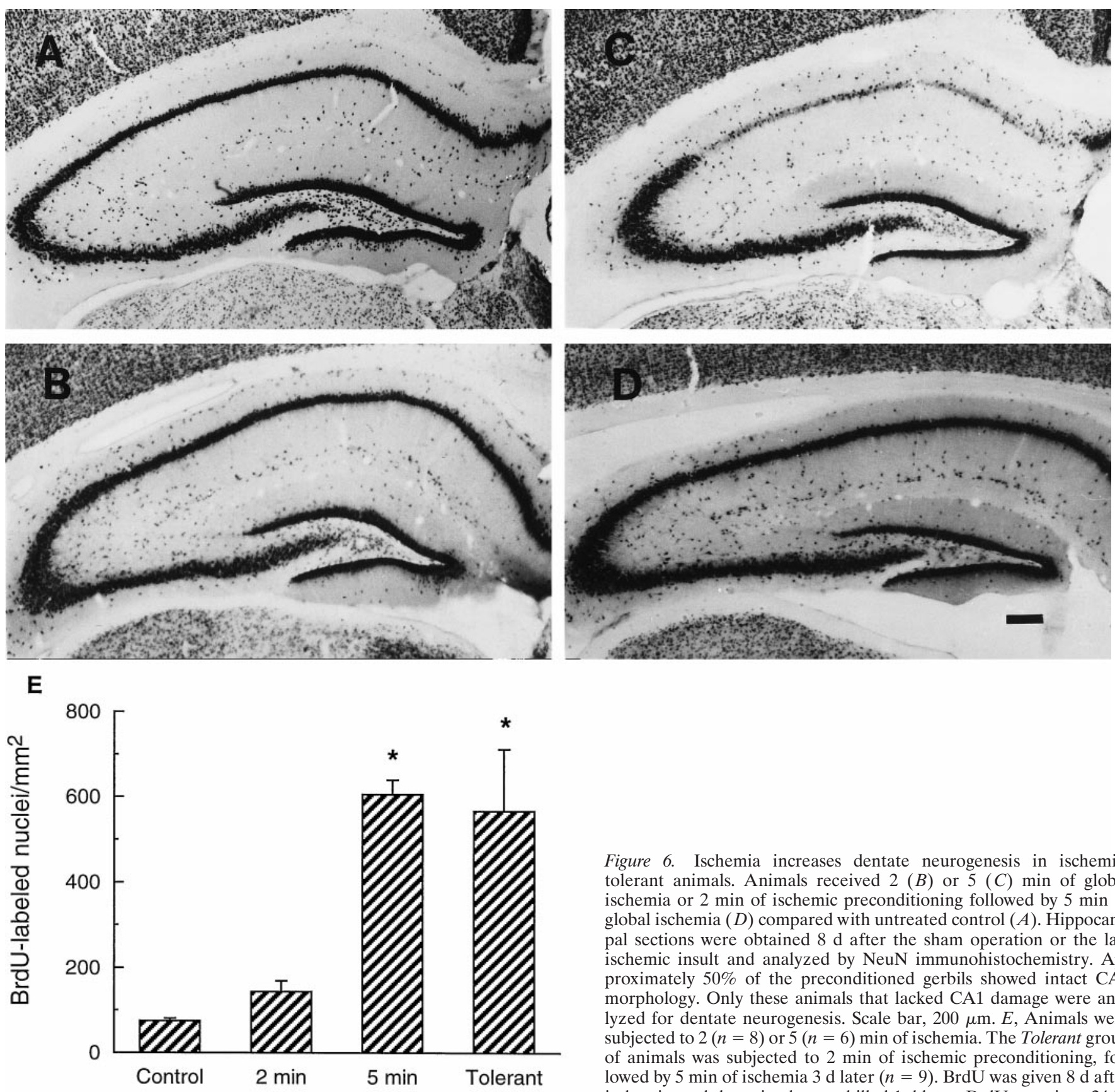

Treatment Condition

Figure 6. Ischemia increases dentate neurogenesis in ischemictolerant animals. Animals received $2(B)$ or $5(C)$ min of global ischemia or $2 \mathrm{~min}$ of ischemic preconditioning followed by $5 \mathrm{~min}$ of global ischemia $(D)$ compared with untreated control $(A)$. Hippocampal sections were obtained $8 \mathrm{~d}$ after the sham operation or the last ischemic insult and analyzed by NeuN immunohistochemistry. Approximately $50 \%$ of the preconditioned gerbils showed intact CA1 morphology. Only these animals that lacked CA1 damage were analyzed for dentate neurogenesis. Scale bar, $200 \mu \mathrm{m}$. E , Animals were subjected to $2(n=8)$ or $5(n=6)$ min of ischemia. The Tolerant group of animals was subjected to $2 \mathrm{~min}$ of ischemic preconditioning, followed by $5 \mathrm{~min}$ of ischemia $3 \mathrm{~d}$ later $(n=9)$. BrdU was given $8 \mathrm{~d}$ after ischemia, and the animals were killed $1 \mathrm{~d}$ later. BrdU was given $24 \mathrm{hr}$ before the control animal was killed (Control) $(n=10)$. Data shown are mean \pm SE. ${ }^{*} p<0.05$ compared with control.

markers after ischemia. Many of these cells may have been undifferentiated because of high rates of proliferation in some subsets of progenitor cells. This is supported by the punctate appearance of BrdU labeling in many cells (Fig. $3 A$, arrows), suggesting that the label had been diluted by several cycles of cell division. Alternatively, some of these cells may have been oligodendrocytes or microglia that were not detected by antibodies against neuronal or astrocytic markers.

In addition to the SGZ, cell proliferation occurs in other parts of hippocampus after ischemia. Previously, we have observed

numerous BrdU-labeled cells in the stratum radiatum, molecular layer, and hilus of the dentate gyrus (Liu et al., 1997) in ischemic gerbils. However, these cells are mostly lectin-positive, suggesting that they are dividing microglia.

BrdU is generally used as a marker for new DNA synthesis (Gage et al., 1995). It is unlikely that cells with DNA strand breaks incorporate enough BrdU to be detected by immunohistochemistry. TUNEL, which detects DNA nicks and strand breaks that indicate DNA damage, labels primarily CA1 neurons and not dentate granule cells after 5-10 min of global ischemia in 
gerbils (Honkaniemi et al., 1996). This pattern of labeling is dramatically different from the pattern observed with BrdU, which primarily labeled cells in the dentate rather than CA1 1 week after ischemia. To confirm that BrdU labeling reflected an increase in cell birth, we also performed experiments using an antibody that recognizes PCNA, which is expressed during cell division. Because this antibody does not recognize PCNA in gerbils, we used mice for these studies. Similar to what we observed for BrdU labeling in gerbils, ischemic mice demonstrated increased numbers of PCNA immunoreactive nuclei in the SGZ after $10 \mathrm{~min}$ of global ischemia.

\section{Possible mechanisms for ischemia-induced neurogenesis in the dentate gyrus}

Neurogenesis in the developing and adult dentate gyrus is regulated, at least in part, by NMDA receptors (Cameron et al., 1995; Gould et al., 1994, 1997). Blockade of NMDA receptors increases the birth rate in the dentate gyrus, even on postnatal day 5 when developmental neurogenesis is at its peak (Cameron and Gould, 1994; Gould et al., 1994). Thus, it is possible that death of glutamatergic neurons that project to progenitor cells induces neurogenesis. In support of this possibility is the observation that removal of excitatory input to granule cells by entorhinal cortical lesions (Cameron et al., 1995; Gould et al., 1997) increases neurogenesis in the dentate gyrus. However, we did not detect neuronal death in the entorhinal cortex after $10 \mathrm{~min}$ of ischemia. This suggests that loss of glutamatergic cells that give rise to the perforant pathway is not responsible for increased neurogenesis in the dentate gyrus after ischemia.

Changes in NMDA receptors may also mediate ischemiainduced neurogenesis. In rats, there is a $20 \%$ reduction in NMDA receptor binding in the dentate gyrus 1 week after transient forebrain ischemia, and 1 week later, NMDA receptor binding returns to control levels (Westerberg et al., 1989; Ogawa et al., 1991). We observed that ischemia-induced neurogenesis in gerbils reached a maximum 9-11 d after ischemia (Fig. 2A) and declined toward control levels $3 \mathrm{~d}$ later. The similarity of these time courses raises the possibility that ischemia-induced decreases in NMDA receptor signaling contribute to neurogenesis in the dentate gyrus. Further studies will be needed to determine whether decreases in NMDA receptor density or function contribute to ischemia-induced neurogenesis in the dentate gyrus.

It is possible that neuronal death within the hippocampus provided a stimulus for increased neurogenesis after ischemia. For example, limbic seizures that cause apoptosis of granule cells (Bengzon et al., 1997) increase dentate neurogenesis (Parent et al., 1997). In addition, excitotoxic and mechanical lesions of the GCL also induce proliferation of neuronal progenitors in the dentate gyrus of the adult rats (Gould and Tanapat, 1997). Granule cell apoptosis was observed by some researchers after forebrain ischemia in the rat ( $\mathrm{Li}$ et al., 1997). Ischemic loss of CA1 neurons might also be a factor, but because dentate neurogenesis was increased in ischemia-tolerant animals in the absence of CA1 cell death, it appears that loss of CA1 pyramidal neurons is not required for dentate neurogenesis. Ischemia also increases the number of TUNEL-labeled cells in the dentate hilus (Johansen et al., 1987; Hsu and Buzsaki, 1993; Honkaniemi et al., 1996; Bering et al., 1997) and causes death of dentate hilar interneurons (Sugimoto et al., 1993; Mody et al., 1995). However, this is apparent after only 2 min of ischemia (Sugimoto et al., 1993), which is not long enough to stimulate dentate neurogenesis (Fig. $2 B$ ). Thus, although death of hilar interneurons may contribute to dentate neurogenesis, it clearly is not sufficient to be the sole cause.

Growth and mitogenic factors could play a role in dentate neurogenesis after ischemia. BDNF and FGF increase the growth and differentiation of dentate granule neurons in culture (Lowenstein and Arsenault, 1996). Basic FGF immunoreactivity increases in hippocampal glial cells $7 \mathrm{~d}$ after ischemia (Endoh et al., 1994). Basic FGF immunoreactivity is also increased in astrocytes in the dentate gyrus after entorhinal lesions (GomezPinilla et al., 1992), which can induce neurogenesis. In addition, FGF receptors are induced in the dentate gyrus after pilocarpineinduced seizures (Gomez-Pinilla et al., 1995), which can upregulate dentate neurogenesis (Parent et al., 1997). Last, hypoxia and erythropoietin stimulate CNS stem cell proliferation in culture (Sorokan and Weiss, 1997). Cerebral hypoxia that accompanies ischemia could induce the expression of erythropoietin in astrocytes (Semenza and Wang, 1992), resulting in erythropoietinmediated increases in neurogenesis in the dentate gyrus. Hence, ischemia-induced changes in FGF, FGF receptors, and other growth factors and their receptors could stimulate increased cell birth observed after ischemia.

\section{Functional consequences of increased dentate neurogenesis after global ischemia}

Neurogenesis has been described in the brains of several adult mammals, including rats and monkeys (Altman and Das, 1967; Bayer et al., 1982; Eckenhoff and Rakic, 1988; Cameron et al., 1993, 1995; Kuhn et al., 1996; Gould et al., 1997). There appears to be neurogenesis in adult human brain, as well (Kirschenbaum et al., 1994). Increased neurogenesis in the dentate gyrus after ischemia could increase the number of granule neurons. There is a substantial increase in the number of dentate granule cells as rodents develop from newborn to adult (Bayer et al., 1982). The NMDA receptor antagonist CGP37849 increases the rate of cell birth in SGZ and the number of granule neurons, without affecting the rate of cell death (Cameron et al., 1995). Mice living in an enriched environment demonstrate increased neurogenesis and have more granule neurons in the dentate gyrus, which correlates with improved learning (Kempermann et al., 1997). In this study, global ischemia increased the birth rate of neural cells with a long survival time in dentate gyrus. This could have resulted in increased numbers of dentate granule cells, at least over the short term. Further quantitative studies will be required to determine whether dentate cell number increases after global ischemia.

The hippocampus plays a pivotal role in learning and memory (Milner et al., 1998). Animals and humans demonstrate memory impairment after ischemic injury to the hippocampus (ZolaMorgan et al., 1992; Squire and Zola-Morgan, 1996). Because cell transplants can reduce memory deficits caused by ischemic hippocampal injury (Hodges et al., 1997; Sinden et al., 1997), it is possible that increased neurogenesis after global ischemia contributes to memory improvement in patients recovering from cerebral ischemia. Newly formed granule cell neurons could extend axons (Stanfield and Trice, 1987), form new synapses on CA3 neuronal targets, and promote recovery of hippocampal function. Long-term studies will be needed to determine whether newly generated neurons form appropriate synapses and if this correlates with improvement function after ischemic damage to the hippocampus. 


\section{REFERENCES}

Altman J, Das G (1967) Postnatal neurogenesis in the guinea-pig. Nature 214:1098-1101.

Bartesaghi R, Gessi T, Migliore M (1995) Input-output relations in the entorhinal-hippocampal-entorhinal loop: entorhinal cortex and dentate gyrus. Hippocampus 5:440-451.

Bayer SA, Yackel JW, Puri PS (1982) Neurons in the rat dentate gyrus granular layer substantially increase during juvenile and adult life. Science 216:890-892.

Bengzon J, Kokaia Z, Elmer E, Nanobashvili A, Kokaia M, Lindvall O (1997) Apoptosis and proliferation of dentate gyrus neurons after single and intermittent limbic seizures. Proc Natl Acad Sci USA 94:10432-10437.

Bering R, Draguhn A, Diemer NH, Johansen FF (1997) Ischemia changes the co-expression of somatostatin and neuropeptide $\mathrm{Y}$ in hippocampal interneurons. Exp Brain Res 115:423-429.

Bernhardt R, Matus A (1984) Light and electron microscopic studies of the distribution of microtubule-associated protein 2 in rat brain: a difference between dendritic and axonal cytoskeletons. J Comp Neurol 226:203-221.

Cameron HA, Gould E (1994) Adult neurogenesis is regulated by adrenal steroids in the dentate gyrus. Neuroscience 61:203-209.

Cameron HA, Woolley CS, McEwen BS, Gould E (1993) Differentiation of newly born neurons and glia in the dentate gyrus of the adult rat. Neuroscience 56:337-344.

Cameron HA, McEwen BS, Gould E (1995) Regulation of adult neurogenesis by excitatory input and NMDA receptor activation in the dentate gyrus. J Neurosci 15:4687-4692.

Deller T, Martinez A, Nitsch R, Frotscher M (1996) A novel entorhinal projection to the rat dentate gyrus: direct innervation of proximal dendrites and cell bodies of granule cells and GABAergic neurons. J Neurosci 16:3322-3333.

Dziewulska D, Kunkler PE, Hunter JD, Kraig RP (1996) Altered neurogenesis in the adult rat dentate gyrus from spreading depression. Soc Neurosci Abstr 390:4.

Eckenhoff MF, Rakic P (1988) Nature and fate of proliferative cells in the hippocampus dentate gyrus during the life span of the Rhesus monkey. J Neurosci 8:2729-2747.

Endoh M, Pulsinelli WA, Wagner JA (1994) Transient global ischemia induces dynamic changes in the expression of bFGF and FGF receptor. Mol Brain Res 22:76-88.

Gage FH, Coates PW, Palmer TD, Kuhn HG, Fisher LJ, Suhnen JO, Peterson DA, Suhr ST, Ray J (1995) Survival and differentiation of adult neuronal progenitor cells transplanted to the adult brain. Proc Natl Acad Sci USA 92:11879-11883.

Gomez-Pinilla F, Lee JW K, Cotman CW (1992) Basic FGF in adult rat brain: cellular distribution and response to entorhinal lesion and fimbria-fornix transection. J Neurosci 12:345-355.

Gomez-Pinilla F, van der Wal EA, Cotman CW (1995) Possible coordinated gene expression for FGF receptor, FGF-5 and FGF-2 following seizures. Exp Neurol 133:164-174.

Gould E, Tanapat P (1997) Lesion-induced proliferation of neuronal progenitors in the dentate gyrus of the adult rat. Neuroscience 80:427-436.

Gould E, Cameron HA, Daniels DC, Woolley CS, McEwen BS (1992) Adrenal hormones suppress cell division in the adult rat dentate gyrus. J Neurosci 12:3642-3650.

Gould E, Cameron HA, McEwen BS (1994) Blockade of NMDA receptors increases cell death and birth in the developing rat dentate gyrus. J Comp Neurol 340:551-565.

Gould E, McEwen BS, Tanapat P, Galea LAM, Fuchs E (1997) Neurogenesis in the dentate gyrus of the adult tree shrew is regulated by psychosocial stress and NMDA receptor activation. J Neurosci 17:2492-2498.

Hodges H, Sowinski P, Fleming P, Kershaw TR, Sinden JD, Meldrum BS, Gray JA (1996) Contrasting effects of fetal CA1 and CA3 hippocampal grafts on deficits in spatial learning and working memory induced by global cerebral ischemia in rats. Neuroscience 72:959-988.

Hodges H, Nelson A, Virley D, Kershaw TR, Sinden JD (1997) Cognitive deficits induced by global cerebral ischaemia: prospects for transplant therapy. Pharmacol Biochem Behav 56:763-780.

Honkaniemi J, Massa SM, Sharp FR (1996) Global ischemia induces apoptosis associated genes in gerbil hippocampus. Mol Brain Res 42:79-88.

Houser CR (1990) Granule cell dispersion in the dentate gyrus of humans with temporal lobe epilepsy. Brain Res 535:195-204.

Hsu M, Buzsaki G (1993) Vulnerability of mossy fiber targets in the rat hippocampus to forebrain ischemia. J Neurosci 13:3964-3979.

Johansen FF, Zimmer J, Diemer NH (1987) Early loss of somatostatin neurons in dentate hilus after cerebral ischemia in the rat precedes CA-1 pyramidal cell loss. Acta Neuropathol (Berl) 73:110-114.

Kaplan MS, Bell DH (1983) Neuronal proliferation in the 9-month-old rodent: radioautographic study of granule cells in the hippocampus. Exp Brain Res 52:1-5.

Kaplan MS, Bell DH (1984) Mitotic neuroblasts in the 9-day-old and 11-month-old rodent hippocampus. J Neurosci 4:1429-1441.

Kaplan MS, Hinds JW (1977) Neurogenesis in adult rat: electron microscopic analysis of light radioautographs. Science 197:1092-1094.

Kempermann G, Kuhn HG, Gage FH (1997) More hippocampal neurons in adult mice living in an enriched environment. Nature 386:493-495.

Kirino T, Tsujita Y, Tamura A (1991) Induced tolerance to ischemia in gerbil hippocampal neurons. J Cereb Blood Flow Metab 11:299-307.

Kirschenbaum B, Nedergaard M, Preuss A, Barami K, Fraser RA, Goldman SA (1994) In vitro neuronal production and differentiation by precursor cells derived from the adult human forebrain. Cereb Cortex 4:576-589.

Kitagawa K, Matsumoto M, Kuwabara K, Tagaya M, Ohtsuki T, Hata R, Ueda H, Handa N, Kimura K, Kamada T (1991) "Ischemic tolerance" phenomenon detected in various brain regions. Brain Res 561:203-211.

Kuhn HG, Dickison-Anson H, Gage FH (1996) Neurogenesis in the dentate gyrus of the adult rat: age-related decrease of neuronal progenitor proliferation. J Neurosci 16:2027-2033.

Li Y, Jiang N, Li D, Chopp M (1997) Granule cell apoptosis and protein expression in hippocampal dentate gyrus after forebrain ischemia in the rat. J Neurol Sci 150:93-102.

Liu J, Solway K, Sharp FR (1997) BrdU uptake into dividing microglia/ macrophages occurs in striatum prior to hippocampus following global ischemia in the gerbil. J Cereb Blood Flow Metab Suppl 17:S422.

Lowenstein DH, Arsenault L (1996) The effects of growth factors on the survival and differentiation of cultured dentate gyrus neurons. J Neurosci 16:1759-1769.

McKay R (1997) Stem cells in the central nervous system. Science 276:66-71.

Milner B, Squire LR, Kandel ER (1998) Cognitive neuroscience and the study of memory. Neuron 20:445-468.

Mody I, Otis TS, Bragin A, Hsu M, Buzsaki G (1995) GABAergic inhibition of granule cells and hilar neuronal synchrony following ischemia-induced hilar neuronal loss. Neuroscience 69:139-150.

Mullen RJ, Buck CR, Smith A (1992) NeuN, a neuronal specific nuclear protein in vertebrates. Development 116:201-211.

Ogawa N, Haba K, Mizukawa K, Asanuma M, Hirata H, Mori A (1991) Loss of $N$-methyl-D-aspartate (NMDA) receptor binding in rat hippocampal areas at the chronic stage after transient forebrain ischemia: histological and NMDA receptor binding studies. Neurochem Res 16:519-524

Parent JM, Yu TW, Leibowitz RT, Geschwind DH, Sloviter RS, Lowenstein DH (1997) Dentate granular cell neurogenesis is increased by seizures and contributes to aberrant network reorganization in the adult rat hippocampus. J Neurosci 17:3727-3738.

Semenza GL, Wang GL (1992) A nuclear factor induced by hypoxia via de novo protein synthesis binds to the human erythropoietin gene enhancer at a site required for transcriptional activation. Mol Cell Biol 12:5447-5454.

Sinden JD, Rashid-Doubell F, Kershaw TR, Nelson A, Chadwick A, Jat PS, Noble MD, Hodges H, Gray JA (1997) Recovery of spatial learning by grafts of a conditionally immortalized hippocampal neuroepithelial cell line into the ischaemia-lesioned hippocampus. Neuroscience 81:599-608.

Sloviter RS (1989) Calcium-binding protein (calbindin-D28k) and parvalbumin immunocytochemistry: localization in the rat hippocampus with specific reference to the selective vulnerability of hippocampal neurons to seizure activity. J Comp Neurol 280:183-196.

Sorokan ST, Weiss S (1997) Erythropoietin mediates increased neurogenesis by embryonic CNS stem cells following a modest hypoxic insult. Soc Neurosci Abstr 131:12. 
Squire LR, Zola-Morgan S (1996) Ischemic brain damage and memory impairment: a commentary. Hippocampus 6:546-552.

Stanfield BB, Trice JE (1987) Evidence that granule cells generated in the dentate gyrus of adult rats extend axonal projections. Exp Brain Res 72:399-406.

Steward O (1976) Topographic organization of the projections from entorhinal area to the hippocampal formation of the rat. J Comp Neurol 167:285-314.

Sugimoto A, Shozuhara H, Kogure K, Onodera H (1993) Exposure to sub-lethal ischemia failed to prevent subsequent ischemic death of dentate hilar neurons, as estimated by laminin immunohistochemistry. Brain Res 629:159-162.
Suhonen JO, Peterson DA, Ray J, Gage FH (1996) Differentiation of adult hippocampus-derived progenitors into olfactory neurons in vivo. Nature 383:624-627.

Weiss S, Reynolds BA, Vescovi AL, Morshead C, Craig CG, van der Kooy D (1996) Is there a neural stem cell in the mammalian forebrain? Trends Neurosci 19:387-393.

Westerberg E, Monaghan DT, Kalimo H, Cotman CW, Wieloch TW (1989) Dynamic changes of excitatory amino acid receptors in the rat hippocampus following transient cerebral ischemia. J Neurosci 9:798-805.

Zola-Morgan S, Squire LR, Rempel NL, Clower RP, Amaral DG (1992) Enduring memory impairment in monkeys after ischemic damage to the hippocampus. J Neurosci 12:2582-2596. 